\title{
Citizen Engagement: A Catalyst for Effective Local Government
}

\begin{abstract}
This project examines the crucial role citizen engagement plays in the local governance process by analyzing various methods of citizen engagement and their direct application to examples in Halifax Regional Municipality (HRM). A literature review and jurisdictional scan was conducted to develop a Best Elements Framework for effective citizen engagement. This identified the seven best elements of citizen engagement, including: timing, use of technology, diversity/representativeness, multiple engagement mechanisms, two-way communication, active community building and accountability/transparency. This framework was then applied to two HRM-based case studies: the HRM Community Engagement Strategy and the HRM Rebranding Strategy. Through analysis of both case studies, the group concluded that the methods utilized were effective overall. Four recommendations were generated for HRM moving forward: creating an annual citizen engagement report card, integrating and expanding online engagement mechanisms, exploring other engagement and evaluation mechanisms, and establish guidelines with community stakeholders for how engagement will impact decision-making.
\end{abstract}

\section{About the Authors:}

Andrew Bucci is a 2015 Master of Public (MPA) Candidate at Dalhousie University. He completed a Bachelor of Arts Degree with a Joint Advanced Major in History and Political Science at St. Francis Xavier University. Andrew is currently a Dalhousie University Senator, and represents the interests of the graduate student community in Senate. His professional interests include law and justice, national defense, and foreign policy and international relations. Andrew is from Newmarket, ON.

Lucy Hulford is a 2015 Master of Public Administration candidate at Dalhousie University and serves as the Vice-Chair and Chair of Programming for the 2015 Atlantic Conference on Public Administration. Lucy completed her Bachelor of Arts in Criminology and English at Saint Mary's University. Her professional interests include defense and procurement policy, public safety and succession planning. Lucy is originally from West Vancouver, BC. 
Alison Macdonald is a 2015 Master of Public Administration (MPA) Candidate at Dalhousie University. Alison has her Bachelor of Arts Honours from Saint Mary's University specializing in the subject of Political Science and Criminology. Her professional interests include foreign policy, risk management, and public sector renewal. Alison is from Cole Harbor, NS.

James Rothwell is a 2015 Master of Public Administration (MPA)/Master of Library and Information Studies (MLIS) Candidate. James earned his Bachelor of Arts Honours from the University of Toronto specializing in the subjects of History and Political Science. His professional interests include public sector renewal, foreign policy, and innovative, sustainable development. James is from Toronto, ON. 


\section{Introduction}

Citizen engagement has long been considered the cornerstone of local government. The strength and main purpose of local government is to represent and protect the everyday interests and needs of citizens, as well as provide them with a democratic forum. Engagement, therefore, is a key aspect to the success of the local democratic process. Local governments of the 21st century must deal simultaneously with old issues and new ones, often in shorter time frames, and with a multitude of stakeholder and citizen interests to balance. In this environment, citizen engagement is more critical than ever before. Exploring current examples of citizen engagement is crucial for understanding its overall importance to the local government process. Ultimately, citizen engagement is an integral part of providing the best programs, services, and infrastructure possible for Canadians at the local level.

The purpose of this project is to identify elements of successful citizen engagement, and use them as a baseline to evaluate past engagement efforts carried out by the Halifax Regional Municipality (HRM). Ultimately, the conclusion drawn is that there are areas for improvement, with recommendations provided for how HRM can strengthen engagement efforts in the future. These were established by reviewing literature, assessing the results from expert interviews, and producing a "Best Elements Framework" from this information. From here, the paper reviews HRM's existing engagement strategy with one case study compared to the established framework, and recommendations provided therein. Before examining the literature review in greater detail however, a necessary overview of the team's methodology and the research limitations is provided.

\section{Methodology}


To identify the best methods of citizen engagement and their application in the HRM, the project team took a sequential approach focused on qualitative research. Our team made the following assumptions:

- Citizen engagement is feasible;

- Citizen engagement is measurable through online indicators, citizen response rates, and after-action surveys;

- There are ways to improve citizen engagement;

- HRM is involved in citizen engagement.

In order to become more familiar with citizen engagement and better identify best practices, our team conducted a broad literature review and concurrent jurisdictional scan. The literature review primarily focuses on peer-reviewed academic journal articles and books written by subject matter experts on citizen engagement. The jurisdictional scan focuses on five major cities and one regional municipality from across Canada, identifying the municipal citizen engagement policy documents for each, as well as any campaigns or platforms used to engage with citizens.

Following the literature review, we establish a Best Elements Framework of evaluation, which could be applied to HRM (and potentially other municipalities). Our team collaboratively evaluated the literature review and jurisdictional scan to identify the best elements of citizen engagement. The Best Elements Framework consists of seven main elements:

- Timing;

- Use of technology;

- Diversity/representativeness;

- Multiple engagement mechanisms;

- Two-way communication;

- Active community building;

- Accountability/transparency.

The framework is used to evaluate the existing HRM Community Engagement Strategy, in particular the strategy background, current citizen engagement policies, and the available 
engagement mechanisms. This is done in order to better assess the steps taken to conduct the Halifax Rebranding campaign. Following this examination, the above Best Elements Framework is applied to evaluate an HRM-based case study, including a background of the case study, an evaluation of mechanisms used, and finally an evaluation based on established framework.

Following evaluation of the case study, our team engaged in semi-structured research interviews with experts: Bruce DeBaie, Managing Director of Corporate Communications at HRM, Councillor Jennifer Watts of District 8, and Mike Bardsley, Brand Strategist at Revolve Inc. Our team then added further background information and made slight modifications to our analysis.

Our team drew conclusions based on our research and analysis, and devised four policy recommendations for how HRM could improve its current citizen engagement practices. Recommendations were made in-line with the SMART principles (specific, measurable, attainable, realistic, and timely).

\section{Limitations}

Our team observed the following limitations in regards to this project:

\section{Timeframe of project:}

Due to the timeframe of the project, certain aspects of research and writing had to be compressed in order to meet academic deadlines.

\section{Interpretation of policies:}

Each team members' bias comes into account in terms of evaluating policies. Although the Best Elements Framework helped mitigate this, there is always some subjectivity when interpreting qualitative policy documents. To ensure a unified vision, our team discussed policy documents in team meetings in order to consolidate perspectives.

\section{Canadian examples:}


Due to the nature of this project, only Canadian cities were examined. A future project may also wish to include some key international examples for a wider comparison and contrast.

\section{Large city examples:}

Although there are some smaller municipalities in the research (e.g. Niagara Region), our team's environmental scan focused mainly on large metropolitan examples due to the availability of resources and information. Expanding the research to additional small municipalities could have provided further useful insight.

\section{Absence of quantitative data:}

Due to the time frame and nature of the project, our team did not gather any quantitative data. Quantitative data gathering was not necessary for the project scope, but future work may want to investigate actual engagement mechanism usage through online surveys and other tools.

\section{Expert interviews carried out after main analysis:}

The interviewees consisted of mid to high-level public servants and policy-makers at the municipal level. Once contact was made, it was a challenge to schedule meetings that fit into our team and the interviewees' schedules. Thus, the interviews were conducted after the bulk of analysis was completed and any modifications to background information and the analysis were made afterwards.

\section{Literature Review}

Throughout the literature, there are a number of definitions and interpretations that elaborate on the concept of citizen engagement. According to the Canadian Policy Research Network's Handbook on Citizen Engagement: Beyond Consultation, "citizen engagement values the right to have an informed say in the decisions that affect their [the citizens'] lives" (Sheedy, 2008, p. 4). Emerging from ideas of public participation, citizen engagement focuses on the sharing of information, power, and mutual respect between governments and their citizens (Sheedy, 2008). Citizen engagement necessitates that the government shares in agenda setting and ensures that policy-making decisions involve public input (MacKinnon et al., 2003). It requires a commitment from government to work with its citizens in a reliable and continuous fashion so 
that they can gain an understanding of the issues in their community, ascertain potential solutions, and provide an opportunity for citizens to use their knowledge to help develop policies and programs that affect them (Lukensmeyer \& Hasselblad, 2006). The benefit of citizen engagement is, as MacMillan (2010) argues, a reduction of the "democratic deficit" ( $p$. 87): governments are able to mobilize citizens and more easily encourage their participation in democracy. As a broader concept, citizen engagement means that citizens are full participants in the policy process, and that their input has truly been given meaningful weight (Turnbull \& Aucoin, 2006).

Much of the literature views citizen engagement as an appropriate mechanism at all stages of the policy process, with Sheedy (2008) in particular noting that it is best seen as an iterative process, "serving to infuse citizens' values and priorities throughout the policy cycle" (p. 4). Sheedy (2008) also states that the potential for engagement goes beyond an informed and actively engaged citizenry. Conducting citizen engagement at the beginning of policy or program development can, among many things, increase citizens' sense of responsibility, lead decision-makers to make better decisions by enabling them to understand social implications of their decisions, and increase the legitimacy of public decisions (Sheedy, 2008, p. 4). Citizen engagement can be executed through a number of forums, such as public consultations and citizen juries. The success of citizen engagement is identified, as Woodford and Preston (2011) note, by both citizen deliberation and influence in the policy development process.

While the literature identifies numerous benefits to participating in citizen engagement, there are also obstacles and challenges that prevent it from becoming fully effective or institutionalized. Indeed, governments often struggle to develop effective strategies for citizen engagement. Generating popular interest in the subject matter or project is critical, as is linking strategy development to the decision-making process. Facilitating methods of citizen engagement without permitting full citizen participation in the decision-making process can be a great hindrance, and discourages future involvement (Boyd \& Lukensmeyer, 2004). Ultimately, the viability of citizen input and opinion must be realistically assessed before government and decision-makers implement modes of citizen engagement. If the opinion of citizens will not impact the decisions made regarding a policy or project, then there is no need to engage them. 
Timing also serves as a significant challenge for citizen engagement. The literature emphasizes the importance of planning citizen engagement activities to allow for sufficient analysis and consideration of citizen input (e.g., Boyd \& Lukensmeyer, 2004; MacMillan, 2010). Citizen engagement must be facilitated early in the policy or project development process to allow decision-makers time to evaluate and include the information and opinions offered by citizens. The challenge of timing also plays a role in the evaluation process. Governments may struggle to assess the results of citizen engagement programs, since their effects do not present in the short term (Speer, 2012). Consequently, developing mechanisms to evaluate long-term success must also be considered when addressing the challenges of timing.

Many detractors of citizen engagement take issue with the perceived reassignment of authority associated with citizen engagement. However, citizen engagement does not aim to remove the authority of government and leadership; instead, it works to acknowledge that many public policy issues are bigger than government (Lenihan, 2009). The importance of government's role rests in exercising their authority to establish effective means of citizen engagement (Lukensmeyer \& Hasselblad, 2006; Lenihan, 2009). It is argued that government and decisionmakers' effectiveness resides in their "ability to use one's authorities and resources to achieve a goal" (Lenihan, 2009, p. 41). Public policy issues require the attention not only of government, but also of an actively engaged citizenry. As such, understanding the importance of all-inclusive democratic participation must act as a guiding principle for citizen engagement.

\section{Jurisdictional Scan}

The jurisdiction scan looked at five major metropolitan governments and a regional municipality from across Canada in order to identify best practices, compare policies, and evaluate current engagement mechanisms used in the local government setting.

\section{City: Vancouver}

Increasing effective civic engagement has been a priority for the City of Vancouver. The city created an Engaged City Task Force on October 3, 2012, with a mandate to "Increase neighbourhood engagement, and improve upon the many ways the City connects with Vancouver residents" (City of Vancouver, 2014a, para. 2). The task force used the 
International Association of Public Participation (IAP2) Spectrum for Public Participation as a guiding principle-i.e. Inform, Consult, Involve, Collaborate, Empower (City of Vancouver, 2014b, p. 12).

Vancouver has taken a grassroots approach, with a focus on building knowledge, capacity, trust, and power in its citizens through community development (e.g. engaging local artists for information dissemination, supporting community and cultural spaces) (City of Vancouver, 2014b). The Task Force published a final report on April 2, 2014, with nineteen recommendations, and a measurable framework for improving engagement. A key recommendation is to ensure citizens have enough information to engage through social media, as well as more traditional mechanisms such as voting. The city remains focused on face-to-face engagement efforts, and reaching out to culturally and linguistically diverse communities (City of Vancouver, 2014a)

\section{City: Edmonton}

The City of Edmonton has taken an innovative and collaborative approach to civic engagement, and has partnered with the University of Alberta to create the permanent Centre for Public Involvement (CPI). The CPI, "through its partner organizations, provides leadership in understanding and applying innovative public involvement ideas, practices and technologies, for citizen participation and deliberation" (Centre for Public Involvement [CPI], 2015a, para. 1). The CPI does this by focusing on building capacity for civic engagement through a communityfocused approach. Moreover, the CPI not only performs research, but also organizes and carries out engagement projects with Edmonton citizens. Such projects include the Civic Spaces Pilot Project, designed to support civic engagement of recent immigrants and refugees through a Civics 101 workshop and open discussion forum with electoral candidates, a Citizen's Jury on Internet Voting, and a Task Force on Community Sustainability (CPI, 2014b).

Within the aforementioned projects, the CPI uses a variety of engagement mechanisms such as Citizen Panels, Citizen Juries, and Citizen Planning Circles, all designed to provide an environment for a small group of citizens to deliberate on a particular set of issues or strategies (CPI, 2014b). All projects have a defined scope and are focused on delivering feasible recommendations to Council. 


\section{City: Niagara Region}

The Niagara Region focuses on planning as the main forum for civic engagement, with an overall goal of better decision-making at the Council level. The Region began a major citizen engagement project in 2013, the 'Imagine Niagara' initiative (Niagara Region, 2015). This initiative is aimed at receiving feedback from the region's residents through social media and online surveys regarding issues such as the environment, transportation, infrastructure, employment, social programming, and the economy (Niagara Region, 2015). As outlined in the initiative's legislation, the goal is to support meaningful participation through dialogue, provide a framework for two-way conversation, and enhance opportunities for civic engagement.

Like the Engaged City Task Force in Vancouver, the Imagine Niagara initiative also follows the IAP2 Spectrum for Public Engagement, with a focus on engaging aboriginal communities (Niagara Region, 2013). The initiative remains dedicated to using plain language in all planning materials (so that citizens can understand and effectively engage on issues), as well as providing a response to all feedback received (Niagara Region, 2013). Committed to measurability, the Niagara Region plans to develop and implement a program for monitoring the effectiveness of all engagement and consultation policies and practices (Niagara Region, 2013). Lastly, Imagine Niagara is linked to the Open Data Niagara Region initiative, with the intention of empowering citizens and other actors to leverage the data in "meaningful and value-added ways" (Niagara Region, 2013, p. 8).

\section{City: Toronto}

The City of Toronto offers a wide variety of services and initiatives to encourage public participation and increase awareness of engagement opportunities for various projects around the city. The main mechanism for achieving these goals is a comprehensive section of Toronto's main website which provides information and educational materials on different ways in which citizens can involve themselves in local government projects (City of Toronto, 2015a). This section, referred to as 'accessing city hall', is well-designed and prominently featured on the website. Unique features of the portal include frequent podcasts providing updates on local initiatives and engagement opportunities, a public consultation calendar and map detailing all 
upcoming events in the area, and extensive educational materials for those looking to understand how local governance works (City of Toronto, 2015b).

Members of the public are invited to engage through a variety of means, including completing surveys, submitting written feedback, and attending public consultations and information sessions (City of Toronto, 2015c). The website also provides users with links to other social media platforms to receive updates on new initiatives in the community. Citizens are able to subscribe to updates via email, Facebook, Twitter, and an e-newsletter circulated every few months (City of Toronto, 2015).

\section{City: Montreal}

In 2002, Montreal created a Democracy Task Force to develop innovative tools designed to promote participation and foster productive interaction between Montreal residents and their city (City of Montreal, 2011). Since its creation, this task force has produced a number of unique policies and guidelines to achieve its vision. In 2006, the task force published the Montreal Charter of Rights and Responsibilities, which highlighted the city's commitment and responsibilities for citizen engagement and spoke to the specific rights of citizens to engage local government. This type of city charter was among the first of its kind in North America (City of Montreal, 2011). Later, the task force amended its charter to include a 'Right of Initiative', which allows citizens to petition any city project or initiative to hold mandatory public consultations once 15,000 signatures have been obtained (City of Montreal, 2011).

The main mechanism employed by the City of Montreal is an integrated website, through which information on a variety of initiatives is provided. It features an interactive map and calendar listing upcoming public consultations, and a selection of educational material on how to get involved in local governance issues (City of Montreal, 2005). The website also connects users to the Office de consultation publique de Montreal (OCPM), which operates as an armslength government organization charged with encouraging public consultations on a variety of municipal issues. While the OCPM website duplicates much of the information and features from the city's primary website, it adds a significant number of valuable features. Through the OCPM website, citizens can see detailed information on various projects, read past reports and findings, and receive updates through a variety of different mediums. 


\section{City: Ottawa}

The City of Ottawa is implementing a new public engagement strategy approved by City Council in December 2013. Currently, there is very little information or infrastructure on the website for citizens to determine where or how they can contribute, and where available, such information is not concentrated in one place. The implementation of the new strategy, while still in its early stages, appears to be a fairly substantial overhaul for the City of Ottawa. Most recently, a draft report of the guidelines and toolkit for the strategy was released for public review and commentary. This report highlights the vision of the new strategy, which seeks to create, "[a] city where public engagement is valued as an important part of the decision making process and is inclusive, meaningful, and responsive to the public's perspectives and needs" (City of Ottawa, 2013b, p.4).

Just as Vancouver and the Niagara Region, the framework being examined for development and implementation in Ottawa is based on the IAP2 Spectrum for Public Engagement (City of Ottawa, 2013b). In particular, they are looking to develop a flexible framework that would enable them to employ a variety of different engagement techniques. The methods listed as potential options include open houses, awareness campaigns, comment forums, symposiums, workshops, study circles, and steering groups (City of Ottawa, 2013b).

\section{Expert Interview Analysis}

The interviewees were asked their thoughts on engagement, the end goal of engagement within the HRM, successful mechanisms for engagement, as well as the relevance and implications of the Halifax Rebranding project. After reviewing the interview responses, three key themes were identified as measures necessary for comprehensive and effective citizen engagement: governance, communication, and credibility.

Both Councillor Jennifer Watts and Bruce DeBaie raised the issue of governance when discussing what citizen engagement means to them. DeBaie noted that engagement allows citizens to participate in the governance process more directly and, in turn, works to create more actively involved and better citizens. Similarly, Watts mentioned that citizen engagement is a key component of the governance process at the municipal level, and emphasized that there is a shared responsibility on the part of citizens and councillors to engage with one 
another. Though Mike Bardsley, speaking from a private sector perspective, did not consider the subject of governance, he mentioned the active citizenry exhibited during the Halifax Rebranding project.

Communication was also highlighted as a critical success factor for citizen engagement by all interviewees. DeBaie drew attention to the use of online tools and the need to capitalize on the HRM's strong web presence. Similar use of technology was raised by Watts who regarded distribution of email newsletters as an effective means to reach out to citizens and initiate the engagement process. Though this does not produce active two-way communication between the Councillor and citizens, it serves to inform citizens of various events and opportunities for further involvement within the community.

Bardsley, referencing practices from the HRM Rebranding project, presented methods for both active and passive engagement communication types. He noted that targeting particular stakeholder groups not only expands the diversity of outreach efforts, but also facilitates greater interaction from citizens whose voices may not always be captured. Understanding varying demographics is also crucial to engagement practices. Bardsley stressed the need to target communication strategies to age and social groups, for example engaging with the elderly through handwritten notes and phone calls. Similar innovative methods of outreach were utilized to increase accessibility for the broader population to participate: street teams sent to various socio-economic centers, and chalkboards setup in public areas represent a few examples.

Credibility was the final theme identified, as interviewees discussed the reaction to the new Halifax logo as well as the political element of citizen engagement. DeBaie contextualized the issue by commenting on the discrepancy in messaging between what citizens want and the decision that Council must make on an issue. Understanding that engagement processes may not necessarily result in the desired outcome of citizens is a challenging point to reconcile given the "we want to hear from you" premise implicit in many engagement practices. DeBaie was adamant in describing the process of establishing credibility as incremental, interactive, and reliant on the ability to manage citizen expectations from the on-set. 
Watts, on the other hand, built on the point of credibility by highlighting the importance of hearing the citizen's voice. She stated that the best outcome is for people to believe that their voice was heard, even if the results are not in their favour. The fact that someone listened to their concerns and opinions and took them into consideration is of great value. When asked how to best balance the political decision-making process with citizen engagement, Watts applauded citizens for their ability to be respectful of the multitude of factors at play. Though he did not explicitly refer to the importance of credibility, Bardsley did comment on the significance of listening to citizens, emphasizing that citizens given the opportunity to provide meaningful feedback are more likely to engage over time.

\section{Framework: Elements of Successful Engagement}

Research on the best practices of citizen engagement points to the need for a framework evaluating effective community engagement. Our team selected seven main factors that affect the successful implementation of citizen engagement. These factors were based upon themes observed in the literature review, expert interviews, and jurisdictional scan.

\section{(1) Timing}

In order for citizen engagement to be effective, citizens must be engaged from the beginning of a policy or program development. This allows citizens the opportunity to provide feedback and act as a key player as the decision-making practices of the project are formulated.

\section{(2) Use of Technology}

Online citizen engagement plays a significant role in the modern democratic process. The Internet has the capacity to renew representative democracy, and holds great potential for increasing citizen engagement at the local government level. Opportunities of online engagement include increased access to information (for both the public and policy makers) and an increase in the number of citizens participating. Technology can create more direct avenues for citizens to hold governments accountable. Technology is a tool that can help to better connect citizens and governments to work with each other, and its effectiveness ultimately depends on the context in which it is applied.

\section{(3) Diversity/Representativeness}


It is important that any public engagement process is representative of the population as a whole. Participation from a diverse group of citizens throughout the citizen engagement process allows representative views and opinions to be considered and act as a balanced influencer for the policy development process.

\section{(4) Multiple Engagement Mechanisms}

Officials can draw citizens into the policy making process between elections; for example, Council may inform citizens, consult with them, and delegate to them. This might occur through mechanisms like citizen juries and referendums. Effective citizen engagement must engage as many different demographics and communities as possible. With social media and Web 2.0 technology becoming ubiquitous, citizens expect to be able to engage with their local government in the same ways. Using multiple engagement mechanism types allows local government to interact with a more diverse spectrum of citizens.

\section{(5) Two-way Communication}

Effective citizen engagement requires an ongoing dialogue, with a mutual exchange of ideas. Having a dynamic relationship between government and its citizens is crucial for active participation within local government, and to ensure shared decision making when appropriate.

\section{(6) Active Community Building}

Involving the community, its interests, and its values within the engagement process has the potential to better inform decisions that will notably impact the public at the local level. Citizen engagement should serve to build knowledge capacity, trust, and power among citizens. These benefits should then be harnessed to improve the community in some recognizable way, so that the efforts put into citizen engagement are rewarding.

\section{(7) Accountability}

Citizen engagement relies on accountability on the part of government, and citizenry. To effectively manage and measure citizen engagement, local government should have policies or reporting mechanisms in place to measure levels of engagement, and recommendations or 
action stemming from engagement. Citizens must also be accountable for their work and suggestions to local government, and must be able to explain, defend, or present their viewpoints to council and/or other municipal bodies.

\section{HRM Community Engagement Strategy}

To better understand the context of the HRM case study, a brief overview of HRM's Community Engagement Strategy is provided here. In January 2006, at a Committee of the Whole meeting, Regional Council endorsed the creation of an HRM Community Engagement program. Further to this, in September 2006 an interim report highlighting the past and present engagement exercises was tabled at Council for review. This process continued into 2007 as an Information Report was published stating that a strategy for HRM public engagement processes would be tabled in Council. Finally, in 2008 the strategy was approved by Council and put into action (Halifax Regional Municipality [HRM], 2008).

This strategy accommodates a combination of short-, medium-, and long-term focuses, each including some of our elements of successful engagement. The short-term strategy required HRM to create an e-newsletter to be sent out to businesses, while the medium-term strategy centred on capacity building as well as improved outreach to citizens. The latter strategy proposed the maximization of website usage along with the development of a community database. Though the HRM webpage and the Shape Your City website have been popular venues for online engagement, it was still noted by Bruce DeBaie that the city is still working to take full advantage of this capacity. Finally, the long-term strategy focused primarily on developing an evaluation method for various citizen engagement practices. Both DeBaie and Councillor Watts indicated they were unaware of any reports or reviews of the strategy and its use having been conducted.

The HRM Community Engagement Strategy is not overly detailed, and fails to meet the various criteria set forth by the framework set out in this paper. Many of the proposed communication techniques are one-way rather than two-way, limiting active participation and 
conversation. For instance, one action item proposed the creation of a strategic communications plan for business units and their divisions. Communication under this practice, would "regularly reiterate the basics of the process such as schedule, milestones, decisionmaking points, progress and opportunities for feedback" (HRM, 2008, p. 18). Another action item sought to improve public knowledge of HRM's processes and structures by facilitating workshops on "volunteering, getting permits" and the creation and distribution of "how-to" guides (p. 19). Though these points are of use to citizens, their formulation does not encourage the active participation of citizens, nor strong two-way communication.

While the strategy has served as a framework for some citizen engagement practices, it has, as Watts noted in her interview, become an out-dated tool and is infrequently referenced during community engagement projects. While it was referenced in the case study discussed below, its overall impact on the process is unclear.

\section{Halifax Regional Municipality - Rebranding Strategy Case:}

In 2011, HRM, in partnership with the Government of Nova Scotia, the Atlantic Canada Opportunities Agency (ACOA), and the Greater Halifax Partnership (GHP), released an economic strategy for 2011-2016 detailing plans to develop Halifax into an economic engine for the region and an internationally competitive city (HRM, 2011). Central to the recommended strategies was a call to develop a unique, international city brand to market Halifax both domestically and abroad. This task was assigned to the GHP for initial research and stakeholder consultation over the next two years to determine how best to proceed (HRM, 2011, p. 20). In July 2013, HRM published a Request for Proposal (RFP) for individuals/firms interested in developing, designing, and delivering a new master brand and strategy for HRM, as well as a broad community and stakeholder engagement program on this topic (HRM, 2013). Built into the RFP was a provision stating that the process was to be guided by the principles of HRM's Community Engagement Strategy (HRM, 2013). Eleven firms responded to the RFP, four of which were shortlisted. In November 2013, the local firm Revolve Branding Inc. was chosen to lead the branding strategy (Lightstone, 2014).

In partnership with the GHP and HRM, Revolve initiated a large public consultation campaign starting in January 2014. The campaign, entitled "Define Halifax Region", focused on engaging 
the public on two principle themes: (1) "What makes the Halifax region unique?", and (2) "What does living in the Halifax region mean to you?" (Brothers, 2014). A variety of unique tools were utilized to engage citizens and obtain their feedback on this subject. Large billboards advertising the campaign and encouraging feedback through social media were set up throughout HRM, with street teams deployed to encourage citizens to leave their thoughts on post-it notes affixed to walls and on chalkboards set up at public events (Revolve Inc., 2014). In addition to these on-the-ground methods, citizens were engaged through multiple websites, social media platforms, focus groups, telephone, online surveys, and even postcards. At the conclusion of the engagement campaign, Revolve and their partners reported that they had connected with over 20,000 residents within the Halifax region from very diverse walks of life (Define Halifax Region, 2014).

Citizens' feedback and commentary was then distilled and Revolve developed a branding concept around the core themes. The overarching vision for the new brand was to "be bold." Revolve promoted it as the largest public engagement campaign ever undertaken in HRM's history (Define Halifax Region, 2014). With the consultations completed and the core themes identified, Revolve developed and unveiled the new brand to HRM City Council in April 2014, where it was unanimously approved. The new branding strategy eliminated the municipality's old designation as 'Halifax Regional Municipality' in favour of 'Halifax'. Though the legal name remains HRM, all marketing and promotional materials will now promote the city brand as 'Halifax', with a new logo featuring a sleeker, more modern look than its predecessor.

However, the recent changes were not without controversy. Many sceptics are unhappy with the final product and disagreed with the removal of 'Regional Municipality' from the name (CTV News Atlantic, 2014). Similarly, the $\$ 217,000$ contract awarded to Revolve-which through related expenses increased to approximately $\$ 300,000$ - has also provoked public criticism; this despite $95 \%$ of the initial contract being dedicated towards public consultation and research (Mosher, 2014).

\section{Analysis of Rebranding Strategy Case:}

Using the established Best Elements Framework, we now evaluate how the citizen engagement component of the rebranding strategy was handled. 


\section{Timing:}

With regards to the timing of the citizen engagement component of the project, Revolve and its partners began the process very early on. Before any designs or concepts were created, citizen feedback was collected to inform the developmental process. This allowed the public to have input and help identify the key features that make HRM a unique place to live and work. By engaging the public in the earliest stages, they acted as a key player to help ensure that the eventual product reflected the overarching views and values of the greater community. The three-month engagement process ensured that citizens had ample opportunity to participate. Moreover, the vast majority of the project's $\$ 217,000$ price tag was devoted towards public consultation and research (Mosher, 2014). This suggests that the citizen engagement efforts were not only timely, but also considered a critical aspect of the process.

\section{Use of Technology:}

The use of technology was another key component of this project. In addition to on-the-ground methods of engaging citizens, online and social media played an enormous role in reaching the broadest possible audience. To that effect, various platforms were used to collect feedback, including websites, Twitter, Facebook, online surveys, etc. Indeed, the organizers of the engagement campaign credit the use of these specific online tools as a main reason why they were able to reach over twenty thousand people (HRM, 2014a). By balancing technological tools and traditional methods of engagement, the risk that people would not be able to contribute was significantly lessened. This factor, in combination with the timing of the process, allowed for the third element of successful engagement to be achieved: representativeness.

\section{Diversity/Representativeness:}

A key concern in the engagement campaign was to ensure that feedback was collected from as many diverse groups within HRM as possible. In an attempt to maximize outreach opportunities, strategic efforts were made to reach out to different social, cultural, and ethnic groups within the community. For example, teams were sent to engage citizens at locations such as Citadel High School, the Spryfield Business Expo, Sobeys at Mumford Road, the Middle Musquodoboit Co-op Store, the Black Cultural Centre, and military bases (Mosher, 
2014). Ensuring that feedback and recommendations were representative of the region overall was essential in the later identification of key themes for developing the new brand and helped ensure the process was inclusive and democratically oriented.

\section{Multiple Engagement Methods:}

As stated previously, a significant variety of tools were utilized during the engagement campaign. The interview with Mike Bardsley revealed that organizers worked with City Councillors to develop specific strategies and mechanisms to best solicit input from individual districts. For example, Councillors suggested ideal locations for street teams to canvass in specific areas. Bardsley also identified that there were a variety of additional activities and engagement methods planned which were not actually rolled out due to various complications (e.g., weather). According to Bardsley, they received consistent feedback from stakeholders and participants that the budget and resources for engagement activities were maximized to their full potential. The broad array of tools used was a determining factor in the success of the engagement campaign.

\section{Two-way Communication:}

The two-way communication component of the rebranding project could have been improved. The process was not an ongoing dialogue; the approach was more akin to a 'question asked and answer recorded' approach. Logistically speaking, this is perhaps practical given the sheer scale of the campaign. Much of the feedback collected was over social media according to Bruce Debaie; of the over 20,000 people engaged, 16,000 gave feedback through various online and social media tools. Although this number is very impressive and a positive indicator for overall support, this type of mechanism is not designed to allow for follow up or clarification. Fortunately, a variety of other tools were used to help better inform the feedback collected (e.g., focus groups). However, after the key themes were distilled and the design created, the public was not brought back into the conversation, with the new brand presented only to a small circle of key stakeholders for the project before it was ultimately presented to HRM's council for approval. This was a further break in the lines of communication. 


\section{Active Community Building:}

Overall the rebranding engagement campaign created a stir within the municipality, to which the overwhelming response through a variety of platforms can attest. As such, the entire rebranding project was a positive and active community-building exercise. The goal was to rally the region behind a single banner that could be used to market HRM's strengths domestically and abroad, although the final result of the project is still controversial, the municipality has a new brand and identity. In recognition of this, the rebranding project can be viewed as a successful example in this category.

\section{Accountability/Transparency:}

The accountability and transparency of the engagement process could have been improved. This largely stems from the aforementioned disconnect between the feedback collected and the final decision made by council. There was no clear map provided for how feedback was to be used to develop the new brand, or how it was to be incorporated in the decision-making process. The public expressed their opinions in the earliest stages, and months later the new logo was unveiled in a top-down manner. This lack of transparency in the final stages of the process may have undermined the goodwill established earlier in the campaign. Indeed, if the decision had been a shared one between Council and the public, the entire process would have been legitimized and both parties could have been held accountable, with critics finding it difficult to argue against the end result.

\section{Overall:}

Despite the few identified areas for improvement, the entire campaign was very successful overall. The engagement campaign was inclusive and accessible to virtually all sectors of society, and got the community involved in discussing what defined them. This exercise raised the bar on engaging citizens within HRM and should be viewed as a positive step towards even greater citizen engagement on municipal issues in the future.

\section{Recommendations:}

Citizen engagement can be a powerful tool for the local democratic process, and can serve as a blueprint for strong, healthy communities and politically active citizens. As shown in the case 
study, HRM has a solid foundation for citizen engagement, but has not followed through or developed its strategies and plans. Thus, its citizen engagement mechanisms are disjointed, with no formal review process in place. Based on our team's research and analysis, the following recommendations are proposed to increase the success of future engagement efforts within the municipality:

Recommendation 1: The HRM should implement an Annual Citizen Engagement Report Card in order to ensure comprehensive follow up on ongoing and completed citizen engagement processes.

The HRM Community Engagement Strategy stated that a Community Engagement Steering Committee, comprised of representatives from various business divisions, would be established to "ensure the recommendations are flexible and suitable to the requirements of their divisions" and work to "oversee the implementation and evaluation of the strategy on an annual basis" (HRM, 2008, p. 23). To date, the creation of such a committee has not occurred and as such, annual reports highlighting the variety of citizen engagement projects undertaken by the municipality have not been executed.

In the future, the implementation of an annual report in the form of a 'report card' could help mitigate the above problem. It would be published both internally to municipal administrators and councillors, as well as externally to the media and citizens. The report could serve to highlight the various engagement projects undertaken by the HRM, the intent of those projects, engagement mechanisms used, and the results. As well, this report card would include feedback from those citizens who participated in the projects and other citizens without affiliation to the projects. The report card itself would act as a mechanism for engagement and feedback from citizens as well as serve to improve the monitoring of these practices and hold the HRM accountable.

Recommendation 2: The HRM should integrate and expand online engagement mechanisms.

The HRM has made progress in diversifying its online engagement through its Shape Your City website, but there is still much work to be done. Indeed, despite the creation of Shape Your City, information and relevant content on citizen engagement remains hard to find, 
scattered between platforms, and lacking functionality. For instance, there is no clearly marked citizen engagement section on the main HRM website, and it is difficult to find links to the Shape Your City or the Halifax Open Data site. Moreover, certain features that should be listed on the Shape Your City site are featured elsewhere, such as the Public Consultations Calendar, which instead is located on the Planning page of the HRM website. As of this publication, the link on the Shape Your City page to the Community Engagement Strategy is broken, and a specific online engagement survey section is non-functional.

Our research has shown that online engagement mechanisms are important for connecting with different communities and demographics. In addition, they remain one of the most costefficient ways of gathering input from citizens. But if these tools are difficult to use, or even non-functioning, then the purpose of using them is defeated. Integration and robust mechanisms are key. In terms of integration, HRM might opt to create a clearly marked landing page in the Residents area of the main HRM website with descriptions of the engagement pages and associated links. At the same time, more robust commenting features and fixing broken links could help improve the online engagement process.

Recommendation 3: The Halifax Regional Municipality should explore other engagement and evaluation mechanisms.

Effective citizen engagement involves capturing the views of all segments and demographics of a given population. Diverse citizen engagement is critical to the quality and effectiveness of the effect of engagement on the policy decision-making process, as diverse views allow for a more robust governance process. There are many ways that local government officials can draw citizens into the policymaking process between elections. Council can inform citizens, consult them, and in some instances delegate to them. This can occur through mechanisms such as citizen juries consisting of a group of broadly representative individuals. These juries are formed to discuss a specific policy issue and participants can call upon experts to help with deliberations. The jury holds no power to implement its verdicts and is an effective consultative function. Currently, the number of engagement mechanisms in HRM is limited.

Looking to our jurisdictional case for the City of Edmonton, we can see the effectiveness of having and using multiple citizen engagement models. Recalling the city's partnership with the 
University of Alberta to create the Centre for Public Involvement (CPI), the use of multiple citizen engagement models is shown to be effective. The CPI organizes and carries out engagement projects with the citizens of Edmonton. These projects involve using a multitude of citizen engagement mechanisms, such as citizen juries and citizen planning circles (CPI, 2014). Providing more types of engagement mechanisms within the HRM, as is seen in the Edmonton model, would serve to greatly benefit citizen engagement within the HRM.

Recommendation 4: The HRM should establish a guideline of decision-making at the outset of projects with community stakeholders to allow for shared responsibility and accountability.

At the onset of each project, HRM should establish clear guidelines for how each stage of an initiative will be connected to the final product or outcome. In this way, the public and key stakeholders can better understand how each project component contributes to the overall process. Linking citizen engagement to the final decision-making process can help increase transparency and accountability for the final results of a given project. From the beginning, the public will be able to understand how their feedback will be used to inform decisions. Similarly, knowing that feedback collected will meaningfully play into the process can encourage more citizens to participate and engage. Furthermore, by drawing clear distinctions between citizen engagement and the final result, accountability is shared between the public and the municipality. This can ultimately help to better inform and legitimize decisions being made at the local level, and ensures a more inclusive and democratic process. Therefore, we propose the following recommendation:

\section{Conclusions}

The overarching goal of this research project is to identify what key elements are conducive to successful citizen engagement, and to evaluate how HRM has conducted its engagement efforts in the past. To determine this, HRM's existing Community Engagement Strategy was surveyed, the HRM Rebranding Strategy case study was examined in relation to a 'Best Elements Framework' that was developed, and the conclusion was drawn that overall HRM is performing positively in the area of citizen engagement. From here, four key recommendations were provided that could help better improve HRM's citizen engagement efforts moving forward. These recommendations include: developing an annual citizen engagement report 
card to evaluate existing efforts; integrating and expanding online tools for engagement; exploring greater engagement and evaluation mechanisms; and establishing clearer guidelines for how engagement efforts will inform decision-making processes. Although this research project attempted to examine citizen engagement within the context of HRM, the findings may also be beneficial to other local governments looking to expand on citizen engagement efforts in other contexts. However, this study represents only one such examination of local government engagement efforts, and further research may yield new findings that are better applicable overall. 


\section{References}

Boyd, A. \& Lukensmeyer, C. (2004). Putting the "Public" back in management: Seven Principles for Planning Meaningful Citizen Engagement. Public Management, 86(7), 1015.

Brothers, P. (2014). Creating a brand for Halifax. Retrieved from http://globalnews.ca/video/1071238/creating-a-brand-for-halifax

Centre for Public Involvement. (2015a). About us. Retrieved from http://centreforpublicinvolvement.com/about-us/

Centre for Public Involvement. (2015b). Projects. Retrieved from http://centreforpublicinvolvement.com/work/labels/projects/

CTV News Atlantic (2014). Goodbye HRM, Hello Halifax: Mixed reaction to bold, new brand. Retrieved from http://atlantic.ctvnews.ca/goodbye-hrm-hello-halifax-mixed-reactionto-bold-new-brand-1.1779311

City of Montreal. (2005). Becoming informed, asking questions, expressing opinions; A practical guide for citizens. Retrieved from http://ville.montreal.qc.ca/pls/portal/docs/PAGE/GUIDE_CONSULTATION_EN/MEDI A/DOCUMENTS/practical_guide_citizens_taking_part_public_consultations.pdf

City of Montreal. (2011). Montreal Charter of Rights and Responsibilities. Retrieved from http://ville.montreal.qc.ca/pls/portal/docs/page/charte_mtl_fr/media/documents/chart e_montrealaise_anglais.pdf

City of Montreal (n.d.). The challenge of participation; Montreal's public consultation and participation policy. Retrieved from http://ville.montreal.qc.ca/pls/portal/docs/page/prt_vdm_fr/media/documents/consult ation_participation_en.pdf

City of Ottawa. (2013a). Public engagement strategy and consultations. Retrieved from http://ottawa.ca/en/city-hall/public-consultations/public-engagement/publicengagement-strategy-and-consultations

City of Ottawa. (2013b). Public engagement strategy: Guidelines and toolkit. Retrieved from http://www.fca-fac.ca/Misc/engstrE.pdf 
City of Toronto. (2015a). Introductory guides to your city. Retrieved from http://www1.toronto.ca/wps/portal/contentonly?vgnextoid=9632acb640c21410VgnV CM10000071d60f89RCRD

City of Toronto. (2015b). Get involved: Consultations. Retrieved from http://www1.toronto.ca/wps/portal/contentonly?vgnextoid=cdf1acb640c21410VgnVC M10000071d60f89RCRD

City of Toronto. (2015c). Get involved: Leaning guides. Retrieved from http://www1.toronto.ca/wps/portal/contentonly?vgnextoid=9632acb640c21410VgnV CM10000071d60f89RCRD

City of Vancouver. (2014a). Mayor's engaged city task force. Retrieved from http://vancouver.ca/your-government/engaged-city-task-force.aspx

City of Vancouver. (2014b). Mayor's engaged city task force final report. Retrieved from http://vancouver.ca/files/cov/final-report-engaged-city-task-force-2014.pdf

Halifax Regional Municipality [HRM] (2011). A greater Halifax: Economic strategy 2011-2016. Retrieved from http://www.greaterhalifax.com/siteghp2/media/greaterhalifax/AGREATERHalifax_Halifax_Economic_Strategy_201116.pdf

HRM. (2008). HRM Community Engagement Strategy. Retrieved from https://www.halifax.ca/council/agendasc/documents/081125cow3.pdf

HRM. (2013). Request for proposal: HRM rebranding project. Retrieved from http://www.halifax.ca/boardscom/SCfinance/documents/Re913Requestforproposal.pdf

HRM. (2014a). Define Halifax Region [Website]. Retrieved from http://www.definehalifaxregion.com/

HRM. (2014b). Shape your city Halifax. Retrieved from: http://shapeyourcityhalifax.ca/shape-your-city-halifax

Lenihan, D. (2009). Rethinking the public policy process: A public engagement framework. Public Policy Forum. Retrieved from: http://www.ppforum.ca/sites/default/files/FRAMEWORK\%20PAPER\%20.pdf

Lightstone, M. (2014). Revolve Snags $\$ 217,000$ Contract to Rebrand Halifax. Chronicle Herald. Retrieved from http://thechronicleherald.ca/metro/1170202-revolve-snags217000-contract-to-rebrand-halifax 
Lukensmeyer, C. J. \& Hasselblad Torres, L. (2006). Public deliberation: A manager's guide to citizen engagement. IBM Center for The Business of Government.

MacMillan, C.M. (2010). Auditing citizen engagement in heritage planning: the views of citizens. Canadian Public Administration, 53(1), 87-106. DOI: 10.1111/j.17547121.2010.00113.x

Mosher, L. (2014). Branding project. Chebucto News. Retrieved from http://www.halifax.ca/district09/documents/ChebuctoNewsforMay2014.pdf

Niagara Region. (2013). AMENDMENT NO. 5 - 2013. Retrieved from http://www.niagararegion.ca/imagine/pdf/engagement-policy-plan.pdf

Niagara Region. (2015). Imagine Niagara. Retrieved from http://www.niagararegion.ca/imagine/

Revolve Inc. (2014). Revolve helps get Halifax talking about Halifax. Retrieved from http://revolve.ca/revolve_helps_get_halifax_talking_about_halifax

Sheedy, A, ed. (2008). Handbook on Citizen CE: Beyond Consultation. Canadian Policy Research Networks. Retrieved from:

http://www.sasanet.org/documents/Resources/Handbook\%20on\%20Citizen\%20Eng agement_Beyond\%20Consultation.pdf

Speer, J. (2012). Participatory governance reform: a good strategy for increasing government responsiveness and improving public services? World Development, 40(12), 23792398. DOI: 10.1016/j.worlddev.2012.05.034

Turnbull, L. \& Aucoin, P. (2006). Fostering Canadians' role in public policy: A strategy for institutionalizing public involvement in policy. Canadian Policy Research Networks.

Woodford, M.R., \& Preston, S. (2011). Strengthening citizen participation in public policymaking: A Canadian perspective. Parliamentary Affairs, 66, 345-363. DOI: 10.1093/pa/gsr065 